\title{
Nucleolin Antagonist IPP-204106N
}

National Cancer Institute

\section{Source}

National Cancer Institute. Nucleolin Antagonist IPP-204106N. NCI Thesaurus. Code C103297.

A synthetic, multivalent, lysine-rich, pseudopeptide and nucleolin antagonist with potential anti-ang iog enic, antineoplastic and pro-apoptotic activities. Upon administration, IPP$204106 \mathrm{~N}$ antag onizes nucleolin leading to a downregulation of cell-surface nucleolin; preventing the binding of certain growth promoting ligands to nucleolin may suppress tumor cell proliferation and angiogenesis. In addition, IPP-204106N is able to translocate to the nucleolus and bind to nucleolar nucleolin. This prevents nucleolin from binding to and stabilizing mRNA of the anti-apoptotic $\mathrm{Bcl} 2$; destabilizing $\mathrm{Bcl} 2 \mathrm{mRNA}$ leads to a reduction in $\mathrm{Bcl} 2$ protein synthesis and induces apoptosis. Further, this agent can antagonize nucleophosmin. Nucleolin, a nucleolar phosphoprotein, is overexpressed on the cell surface of certain cancer cells and binds ligands involved in cell proliferation, adhesion and angiogenesis. 